\section{HARMONIA - RESISTÊNCIA E ACEITAÇÃO}

CHARLES, Príncipe de Gales. Harmony. A Revolução da Sustentabilidade: um novo olhar sobre o mundo. (Trad. de Sabine Holler.) Rio de Janeiro: Elsevier, 2011. 331p.

ISBN: 978-85-352-4200-3.

Tereza Coni Aguiar

Este livro foi encontrado, por acaso, numa das minhas idas à Livraria Galileu, parte de uma programação aos lugares apreciados, no centro do Rio de Janeiro, pela minha amiga, a Profa. Dra. Lívia de Oliveira, numa de suas estadas na cidade. A ideia da resenha partiu dela. Qualifico a obra como preciosa para a linha de pesquisa que venho desenvolvendo há 29 anos, pois tem o mérito de abrir o debate da sustentabilidade sobre nova ótica e de contribuir para amenizar a resistência e ampliar a aceitação do conceito de Harmonia.

Comecei a lidar com o conceito de Harmonia, quando fui trabalhar, em 1985, com a Metodologia de Planejamento do Desenvolvimento Integral e Harmônico para a Área Rural (FERREIRA, 1985) e, desde então, o seu uso me é questionado nos projetos de que participo. A ideia de harmonia encontrava oposição, no meio acadêmico, por parte de pesquisadores que trabalhavam com abordagens distintas (AGUIAR, 2012). Não obstante, apesar das críticas e da relutância em adotá-la, ao longo destes anos, tenho convicção de que, nos dias atuais, o eixo de conhecimento planejamento-desenvolvimentomeio ambiente tem muito a ganhar ao adicioná-la a suas discussões. O parâmetro da Harmonia pode repercutir de maneira relevante como elemento a ser levado em conta nos estudos, na elaboração e avaliação de políticas públicas e na discussão de propostas de soluções para muitos problemas atuais, especialmente aqueles relacionados à sustentabilidade.

O príncipe Charles Philip Arthur George Mountbatten-Windsor, o Príncipe de Gales, se tornou um estudioso da relação do homem com a natureza, preocupando-se, em detalhes, com os impactos causados pelas atividades econômicas nos recursos naturais. Transformou-se em um defensor atuante da Natureza meio ambiente, notabilizando-se por partilhar o seu vasto conhecimento sobre o meio

1 Doutora em Geografia / Consultora para Meio Ambiente e Desenvolvimento. terezaconiaguiar@gmail.com. $\triangle$ Rua Barão de Itambi, 54 apt. 104. Rio de Janeiro, RJ. 22231-000

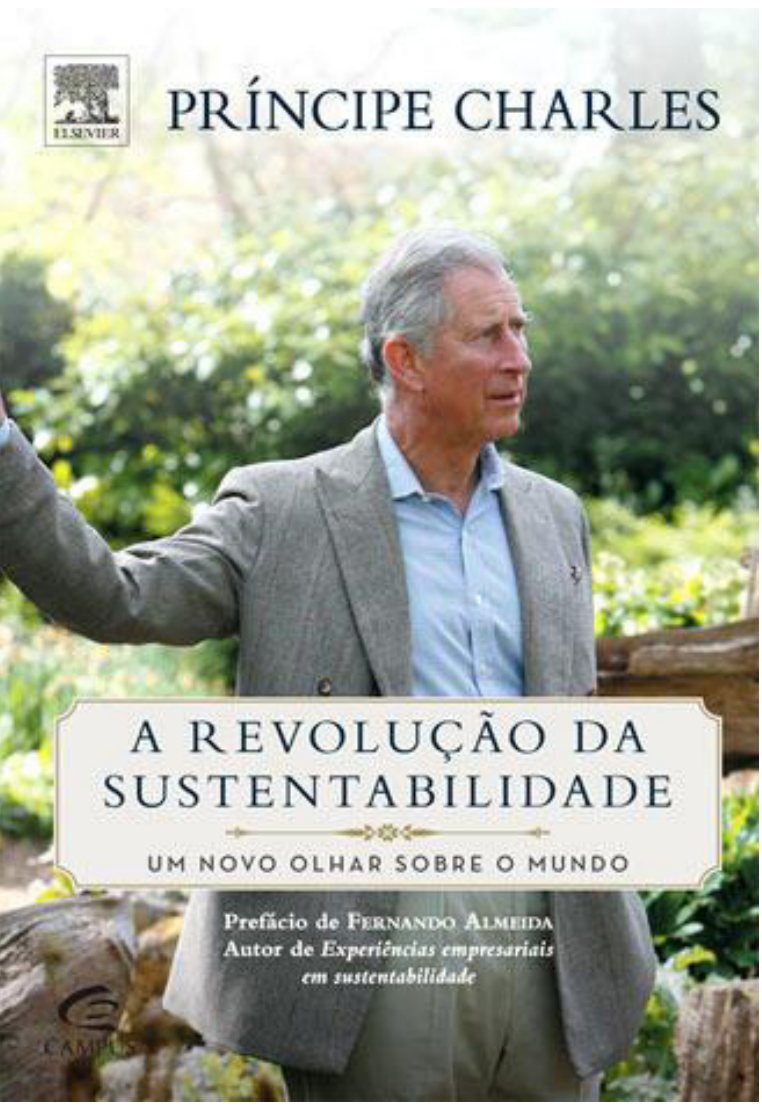

ambiente, obtido nas mais diversas localidades do planeta.

O resultado deste esforço está em seu livro "Harmony", que nos apresenta de que maneira a Sociedade se desconectou da Natureza e como esta conexão se tornou necessária nos dias atuais para diminuir os problemas ambientais e promover a sustentabilidade no mundo. Seu ponto alto centra-se na explicação do funcionamento da harmonia e na 
apresentação de numerosas experiências exitosas para os problemas ambientais recentes.

Tomar conhecimento do seu conteúdo é, portanto, um incentivo para participarmos de ações, com uma nova visão sobre a integração Sociedade/Natureza, a fim de mudarmos a maneira como percebemos o mundo e como atuamos nele e de buscarmos formas de recolocar a Natureza no seu lugar de direito. É também um apelo para procurarmos as melhores soluções para os inúmeros problemas ambientais que a Sociedade enfrenta. Estes estão tão enraizados na vida dos indivíduos que nem percebemos como surgem.

A obra, composta de 331 páginas, está dividida em sete capítulos. O primeiro, Harmonia, mostra a finalidade do livro e se destaca por fazer um convite à participação ativa em prol da sustentabilidade. Este apelo se fundamenta no fato de os problemas ambientais e sociais terem chegado ao seu limite e não poderem ser solucionados, se forem mantidas as mesmas práticas que os ocasionaram. O autor propaga a "revolução da sustentabilidade" para a qual afirma ser urgente que sejam tomadas as providências que estão ao nosso alcance a fim de alterarmos nossa percepção do mundo e a maneira como atuamos. Para este engajamento, é necessário desenvolvermos o pensamento da harmonia que envolve o senso claro de proporção e equilíbrio, bem como uma visão holística, integrado com a apreciação da beleza natural. A ideia de harmonia preconiza que não estamos separados da Natureza, somos parte dela e abrange "princípios que geram o estado ativo de equilíbrio". Inclui o respeito aos ritmos e padrões da Natureza, a integração das partes com o todo e os limites que ela apresenta.

$\mathrm{Na}$ atualidade, os diversos setores das atividades econômicas e as ocupações humanas se afastaram muito destes princípios. A observação de como se verifica o funcionamento da Natureza, adquirindo-se conhecimentos filosóficos nesta aproximação, é um ponto fundamental neste processo de mudança de pensamento, em prol de uma atuação a favor da sustentabilidade. Colabora, nesta transformação, o entendimento do conceito de desenvolvimento, como um processo que abarca muitos aspectos interligados. Os problemas na atualidade devem ser compreendidos num contexto de desenvolvimento amplo, não estritamente preocupado com o crescimento econômico.

Nos seis capítulos seguintes, o autor expõe várias questões: os impactos ambientais e suas consequências em diversas partes do mundo; os padrões ditados pela Natureza, destacando a relevância de compreendê-los. Envereda, ainda, numa retrospectiva que trata da passagem ocorrida entre o pensamento da harmonia e a visão fragmentada do mundo. Neste percurso, as resistências à mudança são apontadas de forma minuciosa, expondo as soluções encontradas na atualidade e as experiências concretas, que foram visitadas, em várias partes do mundo, e que já utilizam o princípio da conexão e da harmonia.

A leitura da obra nos leva a conhecer os inúmeros impactos ambientais, que se sobressaem pelas graves consequências que ocasionam. Este conjunto de danos assinala de modo inequívoco que o planeta está diminuindo sua capacidade de atender às novas necessidades que a sociedade apresenta. A grande demanda por água, pelos diversos setores econômicos e pelo intenso processo de urbanização e, ainda, o desmatamento com a extinção da fauna e da flora em vários ecossistemas são exemplos desta situação limite em que vivemos.

As formas e os padrões ditados pela Natureza e a importância de se compreendê-los são bem explorados no capítulo em que o autor visita o passado e as antigas civilizações, citando inúmeros exemplos em obras como: catedrais, templos, instrumentos antigos e, inclusive, 
na música, em que os padrões da Natureza eram seguidos. Seguese o relato das perdas significativas para a humanidade, como a sabedoria e o patrimônio espiritual, comuns aos povos mais antigos. Estes exemplos situam o leitor quanto ao crescimento econômico desvinculado da Natureza, de maneira generalizada e excessiva.

A mudança do pensamento da harmonia para o pensamento mecanicista, caracterizado pela visão fragmentada do mundo é tratada nolivro, fazendo-se menção ao período em que começa a imperara ideia de se explorar a Natureza e dominar-se o seu funcionamento. Nesta parte é analisada a trajetória da abordagem da Natureza na ciência, permitindo-se, ao leitor, compreender a passagem da visão global para a visão reducionista e o seu predomínio na sociedade. Através desta análise, podemos entender como os estudos sobre o funcionamento dos organismos vieram privilegiar a separação de seus elementos e levar as diversas disciplinas a terem seu próprio desenvolvimento. A partir deste período, a Natureza passa a ser considerada externa à Sociedade e mera fornecedora de recursos naturais e de matéria-prima. Com a expansão desta visão, o modo de vida na sociedade veio a ser cada vez mais desconectado, dominando todos os seus segmentos: econômico, político, social e cultural. A advertência feita pelo autor é clara: é preciso alterar este modelo mental e iniciar um processo de reduzir a desconexão.

Recentemente, muitas pesquisas, em variados campos científicos, têm revelado a interconexão profunda dos fenômenos no mundo físico. Já existem diversas experiências concretas em vários países, utilizandose deste princípio e que foram visitadas pelo autor. São projetos a serem divulgados, pois afirmam a possibilidade de a sociedade mudar, recuperando o sentido da harmonia e da sustentabilidade.

Neste aspecto, o leitor contará com a descrição detalhada de numerosos casos bem sucedidos que são relatados, explorando soluções para os principais problemas que a sociedade enfrenta na atualidade. A apresentação destas experiências é valiosa, pois, ao assinalar seus resultados positivos, nos encoraja a fazer propostas e a pensar novas prioridades com a finalidade de desenvolver ações que contribuam para a criação de um novo modelo de desenvolvimento.

Para deixar claras as possibilidades efetivas de mudança dentro de parâmetros inovadores, o autor faz um extenso percurso, descrevendo estas iniciativas que foram realizadas em diversos setores de vida moderna: agricultura, alimentação, produção de orgânicos, criação de animais, melhorias materiais do solo, arquitetura sustentável, novos produtos industriais, saúde, planejamento e soluções urbanas. Nestes exemplos, podemos observar como, na contemporaneidade, as pessoas, através de projetos em vários campos, estão tentando estabelecer um relacionamento harmonioso com os sistemas naturais. A relevância de apoio e de financiamento a projetos com novos parâmetros é uma prioridade, uma vez que as decisões do planejamento, nos diversos países, não acompanharam as exigências que a sociedade tem feito. A ênfase destas instituições governamentais ainda recai sobre diretrizes, cuja preocupação central é promover o crescimento econômico.

Outro tópico do livro, que nos desperta grande interesse, refere-se às pesquisas científicas que comprovaram a necessidade do contato com a Natureza para se ter bem-estar. Os resultados positivos obtidos com estas experiências nos surpreendem. Comprovam que o alcance do bem- estar depende de questões ligadas à saúde e ao ambiente construído e, também, de uma série de condições como: alimentação saudável, senso de comunidade, qualidade do entorno, contato com a natureza, além do senso de lugar.

Nestas experiências, observamos que a importância dos espaços verdes e de áreas naturais foi mais uma vez revalorizada. Além das 
diversas vantagens que se obtêm com estes espaços, de forma direta ou indireta, e de seu uso como área de lazer e de entretenimento, a sua existência tornou-se, também, condição para a redução do índice de determinadas doenças (cardíacas, por exemplo) e para o aumento da longevidade. Estas constatações acentuam o papel dos chamados serviços ecossistêmicos, que agregam uma gama de benefícios extraídos dos sistemas naturais, quando apresentam o seu funcionamento de modo adequado.

As ideias destacadas pelo autor sobre o papel do lugar, como um conceito que colabora na definição de soluções, encontram forte afinidade com a Geografia Humanista. De acordo com esta abordagem, as discussões para definição de diretrizes do planejamento edas políticas públicas devem levar em conta o amor ao lugar, o elo afetivo entre as pessoas e o ambiente e, ainda, a noção de conforto, as sensações e os valores. As pesquisas na Geografia Humanista destacam a dimensão simbólica dos lugares e valorizam a preocupação de se entender o ambiente, incluindo seus encantamentos, estética, personalidade, distinção e magia, itens também destacados pelo Príncipe Charles, como integrantes do pensamento da harmonia.

Considero que a temática trazida pelo livro "Harmony" interessa a todos os campos do saber, mas sem dúvida colabora de forma significativa com aqueles que trabalham com a perspectiva humanista e que têm, no desenvolvimento harmônico e no meio ambiente, seu foco principal de preocupação.
Muito se reage às propostas de retorno às práticas que enfatizam o respeito à harmonia e háquem consideretais iniciativas como negativas, pois podem impedir o progresso. Entretanto, esse entendimento não é apropriado, pois a revolução da sustentabilidade significa substituir a busca de crescimento econômico ilimitado e concorrência pela meta de bem-estar e cooperação. Seus objetivos devem ser centrados na satisfação das necessidades e não no aumento cada vez maior do consumo. $\mathrm{O}$ argumento que o Príncipe Charles contrapõe é o de que continuar como estamos não é uma opção válida e a consequência será um mundo ainda mais dividido e ecologicamente degradado. Como ele bem enfatiza: "nenhuma parte pode crescer bem sem relacionarse e estar de acordo com o bem-estar do todo" (CHARLES, 2011, p. 139).

\section{REFERÊNCIAS}

AGUIAR, Tereza Coni. Metodologia de Análise Socioeconômica para Planejamento Ambiental: uma contribuição à Interação Sociedade/ Natureza. Niterói: [s.n.], 2012, 232f. Tese (Doutorado em Geografia): Universidade Federal Fluminense, 2012.

FERREIRA, Mara. et al. Metodologia de Planejamento para Área Rural. Paracambi - RJ: Fundação para o Desenvolvimento da Região Metropolitana do Rio de Janeiro - FUNDREM, Rio de Janeiro, 1985. 